\title{
The motivational profile does matter: an exploratory survey on the influence of remote office work on physical behavior during the COVID19 lockdown
}

\section{Miriam Cabrita ( $\sim$ m.cabrita@rrd.nl)}

Roessingh Research and Development https://orcid.org/0000-0001-6757-9406

Roos Bulthuis

Roessingh Research and Development

Monique Tabak

Roessingh Research and Development

Research article

Keywords: work, occupational health, physical activity, eHealth, covid-19, motivation

Posted Date: March 18th, 2021

DOI: https://doi.org/10.21203/rs.3.rs-150692/v2

License: (c) This work is licensed under a Creative Commons Attribution 4.0 International License.

Read Full License 


\section{Abstract}

Background: Most office workers were forced to work remotely due to the COVID-19 global pandemic, possibly leading to a reconfiguration of settled patterns of physical behavior, often characterized by a sedentary lifestyle. This study aimed to investigate the motivational profile, facilitators, and barriers that might have influenced a change in physical activity while working remotely due to the COVID-19 lockdown.

Methods: An online questionnaire was distributed in May-June 2020 including demographics, selfreported physical- and work behavior throughout the day before and during the lockdown, Sports Motivation Scale-II assessing motivation for being physically active, and rating on facilitators and barriers for engaging in physical activity during the lockdown. One-way ANOVA with Tukey post-hoc test was computed to investigate differences between those participants who become more-, less-, and equally active during the COVID-19 lockdown.

Results: Ninety-nine people (Female=66) completed the questionnaire. Forty-four percent of the participants considered themselves less active than before the lockdown. Respondents reporting becoming more physically active $(28 \%)$ were more intrinsically motivated than the remaining participants. The most important facilitators for physical activity were 'good weather', 'no work-related travel', and 'flexible work schedules'. The most important barriers were 'no active transportation', 'closed facilities', and 'work fatigue'.

Conclusions: Strategies that adapt to the weather and fit the work schedule could facilitate physical activity among remote office workers. The results of this study will be used to design interventions to promote an active lifestyle among office workers, personalized to their motivation profile, needs, and preferences.

\section{Background}

Physical inactivity is the fourth leading global risk for mortality in the world (1). Urbanization, the increase in passive modes of transport, and the increase in sedentary behavior during occupational and leisure activities are some of the reasons pointed out for the global increase in physical inactivity. Office workers, also referred to as white-collar workers, are particularly susceptible to a sedentary lifestyle as their work requires long, and uninterrupted periods of sitting $(2,3)$. Prolonged sitting periods often lead to neck-, lower back- and shoulder pain $(4,5)$, with the prevalence of musculoskeletal symptoms among office workers being above $63 \%$ (5). Although some of these conditions are temporary, they often lead to chronicity and consequent socio-economic burden (6). Studies in physical activity patterns suggest that office workers, and in particular high-educated individuals, often fit a weekend warrior profile (7-9), characterized by trying to compensate for the low physical activity during the workdays with high engagement in moderate-to-vigorous physical activity during non-work days (7). While some studies report that compiling all the exercise activities in 1-2 sessions a week may be sufficient to reduce all- 
cause mortality $(10,11)$, it remains unclear whether such exercise sessions can reverse the damage caused by long periods of sitting (12). In this line, many strategies to promote health and wellbeing among office workers target the disruption of long sitting periods at the office and the promotion of short sessions of light physical activity. While some of these interventions focus on workstation adaptation (e.g. $(13,14))$, counseling sessions with coaches (e.g. (15)), or promote more sit-to-stand variation (e.g. (13)), a growing number of technology-based interventions, also called eHealth or digital health interventions, is being developed to promote breaks in sedentary behavior among office workers (e.g. (16, 17)). However, current interventions targeting the promotion of physical activity and interruption of inactivity among office workers do not consider situations of flexible work (i.e., working partly from home). As an example, while interventions at the workplace can rely on the role of peer pressure - for example by promoting walking-meetings or collective lunch walks - when working from home the individuals need to find the motivation themselves to incorporate active breaks in their daily work.

The COVID-19 outbreak caused abrupt changes in the lifestyle and wellbeing of the global population, also to those who were not infected with the virus. Many countries have required their citizens to stay at home during national lockdowns to minimize the spread of this infectious disease (18). As a consequence, office workers were asked to work from home whenever possible, facilities for sports and exercising were closed, and group activities were canceled. This reduced the opportunity to participate in physical activity and, combined with increased stress and anxiety, favored less active lifestyles $(19,20)$. However, fitness tracker companies reported an increase in the logging of indoor sport-related activities. For example, one of the global largest producers of activity trackers reported that the number of steps worldwide was reduced by $12 \%$ in April 2020 compared to the same month in 2019, but that steps from workout activities were increased by $24 \%(21)$. This change in the activity patterns suggests that some individuals have found strategies to be physically active while working remotely.

Perceived facilitators and barriers to engaging in physical activity may affect someone's physical behavior and susceptibility to change this behavior (22). The main facilitator for physical activity is the convenient availability of activities and facilities (23-25). Another facilitator could be having children, as parents want to serve as role models and spend active time with their children $(26,27)$. According to Borodulin and colleagues (28), barriers to physical activity may differ depending on employment status, age, and family status. A major barrier constraining physical activity among employed adults is a high work demand or lack of time $(23,24,26,27,29-31)$. Other barriers found in literature are lack of facilities $(23,24,26,27,29,30)$, health reasons $(23-25,30-32)$, family obligations $(26,27)$ and lack of motivation $(27,28,31,32)$. Motivation to be physically active in the frame of the Self-Determination Theory (33) differentiates between six motivation profiles: a-motivation, external, introjected, identified and integrated regulations, and intrinsic motivation (34). A recent study showed that the motivation to engage in healthy behaviors may influence the preference for persuasive features included in technology-based applications (35). The study by van Velsen and colleagues showed that intrinsically motivated users appreciated all persuasive features, while externally regulated users were mostly motivated by particular persuasive features, such as showing progress, self-goal setting, rewards in the form of compliments, and health education (35). 
In this paper, we hypothesize that the extent to which the individuals found strategies to incorporate physical activity in their daily life during the COVID-19 lockdown was influenced by (1) motivation to be active, and (2) perceived facilitators and barriers to incorporate physical activity while working from home. The research presented in this manuscript is very timely as the COVID-19 lockdown provides an opportunity to research how remote working influences physical behavior, as most office workers were forced to work from home. To date, the impact of flexible work (i.e. working partly from home) has been scarcely investigated in the literature, with some indication that flexible work does not impact physical activity but increases sedentary behavior (36). Considering that fully remote or flexible work has become the normal way of working for office workers in many countries, the results of this study are of high relevance to understanding how to define new strategies to promote physical activity in the daily life of office workers adapted to the remote working setting. Particularly, by identifying the facilitators and barriers perceived by office workers to engage in physical activity while working remotely during the COVID-19 lockdown, we could tailor health promotion interventions to tackle these questions and help the worker find strategies to reach an active lifestyle. The results of this study will be used in the development of technology-based interventions promoting an active lifestyle among office workers.

\section{Methods}

The objective of this study is to investigate the motivational profile, facilitators, and barriers that influenced an eventual change in physical activity while working remotely due to the COVID-19 lockdown. An online questionnaire was developed consisting of four sections:

1. Demographics of the participants (including gender, age, living situation, country of residence, and country of employment);

2. Self-reported change in physical activity during the COVID-19 lockdown. Participants were asked whether they perceived themselves as becoming more-, less-, or equally physically active compared to before the COVID-19 lockdown;

3. Motivational profile of the participant in regards to the engagement in physical activity, assessed with the Sports Motivation Scale-II (34);

4. Identification of facilitators and barriers for engaging in physical activity during COVID-19 lockdown. Participants rated to which extend each facilitator stimulated them to be active and to which extend each barrier limited them to be active when they were working from home (on a 1-5 Likert scale, with 1 is "completely disagree" and 5 is "completely agree"). The initial list of facilitators and barriers was drafted based on literature (23-32), selecting those factors that were relevant for remote office work. A list of 16 facilitators and 17 barriers in the categories 'physical', 'psychological', 'work context', and 'home context' was drafted. This list was piloted as a test questionnaire among 21 experts on the promotion of healthy behaviors who indicated whether each facilitator and barrier applied to their situation as an office worker. Based on the pilot study, a final list of 9 facilitators and 13 barriers was created in the categories 'physical', 'psychological', 'working from home', and 'social distancing'. 
The survey was distributed in May and June 2020 via social media and personal networks. Informed consent was collected before the start of the questionnaire. This study did not require the approval of the Medical Ethical Review Board, according to the Dutch Medical Research Involving Human Subjects Act (WMO) (37), as all subjects were competent individuals and the study did not involve any interventions or treatments. Only completed questionnaires were used in the analysis. Data from participants younger than 18 years old and who could not, at least partly, work from home during the COVID-19 lockdown were excluded. Data were processed and visualized using Microsoft Excel 2019 and SPSS version 19. The individual motivation profile scores in the six dimensions assessed by the SMS-II - intrinsic motivation, integrated regulation, identified regulation, introjected regulation, external regulation, and a-motivation were computed calculating the average score of the corresponding three items of the scale. A score for extrinsic motivation was calculated combining the responses to the items on integrated regulation, identified regulation, introjected regulation, and external regulation, following the Self-Determination Continuum (38). The predominant motivational profile for each participant was calculated by identifying the profile with the highest score. For example, a participant who scored higher on intrinsic and extrinsic motivation than on a-motivation was considered as predominantly intrinsically motivated. To investigate the differences in the score of intrinsic motivation, extrinsic motivation and a-motivation, and the perceived change in physical activity during COVID-19 lockdown (more-active, equally-active, or lessactive), we performed a one-way ANOVA with Tukey post-hoc test. For the statistical analyses, the level of significance was set at $p<0.05$.

\section{Results}

In total, 127 people started the questionnaire. The data analysis comprised the responses of 99 participants ( 66 female), after cleaning up for incomplete questionnaires and unfit inclusion criteria. Almost half of the participants were in the age range $25-34$ years $(44 \%)$ and $19 \%$ of participants were aged between 35 and 44 years old. Most participants were living with a partner or with a partner and children ( $46 \%$ and $26 \%$ respectively). Other living situations included living alone (15\%) or living in a student house or with parents (13\%). Around $75 \%$ of the participants were living and working in the Netherlands. Those not living and working in the Netherlands listed Greece $(n=8)$, United Kingdom $(n=$ 3), Germany $(n=8)$, Spain $(n=2)$, Portugal $(n=1)$, Belgium $(n=1)$, and Ireland $(n=1)$ as living and/or working country. Table 1 provides an overview of the demographic characteristics of the included participants.

Table 1: Basic characteristics of study participants. 


\begin{tabular}{|c|c|}
\hline Characteristic & $\mathbf{N}(\%)$ \\
\hline \multicolumn{2}{|l|}{ Gender } \\
\hline Male & $33(33 \%)$ \\
\hline Female & $66(67 \%)$ \\
\hline \multicolumn{2}{|l|}{ Age } \\
\hline $18-24$ & $13(13 \%)$ \\
\hline $25-34$ & $44(44 \%)$ \\
\hline $35-44$ & $19(19 \%)$ \\
\hline $45-54$ & $10(10 \%)$ \\
\hline $55-64$ & $13(13 \%)$ \\
\hline \multicolumn{2}{|l|}{ Living situation } \\
\hline Alone & $15(15 \%)$ \\
\hline Together with partner & $45(46 \%)$ \\
\hline Together with partner and children & $26(26 \%)$ \\
\hline Other & $13(13 \%)$ \\
\hline \multicolumn{2}{|l|}{ Working Country } \\
\hline The Netherlands & $72(72 \%)$ \\
\hline Other & $18(18 \%)$ \\
\hline
\end{tabular}

Twenty-seven percent of the participants considered becoming more physically active during the lockdown - the more-active group. Twenty-eight percent did not perceive a change in physical activity level - the equally-active group, and $44 \%$ considered becoming less active - the less-active group. In general, participants scored high on introjected regulation (mean 5.08, SD 1.06), integrated regulation (mean 4.66, SD 1.43), identified regulation (mean 4.48, SD 1.49), and intrinsic motivation (mean 4.02, SD 1.50) and scored low on external regulation (mean 2.24, SD 0.99) and a-motivation (mean 2.19, SD 1.19). When comparing the motivational profile with the perceived change in physical activity during the COVID19 lockdown, the more-active group scored significantly higher than the less-active group on intrinsic motivation (mean difference $=0.91, p<0.05$ ) and on identified regulation (mean difference $=0.89, p<$ $0.05)$. The less-active group scored significantly lower than the equally-active group on identified regulation (mean difference $=-1.05, p<0.01$ ) and higher on a-motivation (mean difference $=0.84, p<0.01$ ) . After grouping the components of extrinsic motivation (integrated regulation, identified regulation, introjected regulation, and external regulation) into a single score, the equally-active group scored significantly higher on this motivational profile than the less-active group (mean difference $0.56, p<$ 0.05). Figure 1 illustrates the comparison of the scores in intrinsic motivation, extrinsic motivation, and amotivation per group of perceived change in physical activity during the COVID-19 lockdown. 
The computation of the predominant motivational profile of each participant resulted in 45 participants given allocated to the intrinsic-motivated group, 45 participants to the extrinsic-motivated group, and 9 participants to the a-motivated group. The a-motivated group was mostly composed of participants who perceived becoming less active while working remotely $(\mathrm{N}=7,78 \%)$. Almost half of the participants in the extrinsically motivated group reported becoming less active $(\mathrm{N}=20,44 \%)$ followed by equally active $(\mathrm{N}=16,36 \%)$. The intrinsic-motivated group was the most heterogeneous in terms of perceived change in physical activity with 17 participants reporting becoming less active (38\%) and the other 17 reporting becoming more active (38\%).

Table 2 summarizes the average scores given to the facilitators and barriers per group on reported change in physical activity during the COVID-19 lockdown. In general, the equally-active group scored the facilitators higher than the more-active and less-active group (mean $=3.09$ compared to 3.04 and 2.72, respectively). In turn, the less-active group scored the barriers higher than the equally-active and moreactive groups (mean $=2.63$ compared to 2.02 and 1.90, respectively). The highest scored facilitators by the more-active group were (1) no work travel, (2) good weather, and (3) flexible work schedule. The highest scored barriers by the less-active group were (1) no active transportation, (2) closed sports facilities, and (3) time spent on household chores.

Table 2: Mean scores of facilitators and barriers to physical activity during the COVID-19 lockdown separated by a perceived change in physical activity. 


\begin{tabular}{|c|c|c|c|c|c|c|c|c|}
\hline & \multicolumn{2}{|c|}{$\begin{array}{c}\text { less-active } \\
(\mathrm{N}=44)\end{array}$} & \multicolumn{2}{|c|}{$\begin{array}{l}\text { equally-active } \\
\qquad(\mathrm{N}=28)\end{array}$} & \multicolumn{2}{|c|}{$\begin{array}{c}\text { more-active } \\
(\mathrm{N}=27)\end{array}$} & \multicolumn{2}{|c|}{ all } \\
\hline & mean & SD & mean & SD & mean & SD & mean & $\mathrm{SD}$ \\
\hline \multicolumn{9}{|l|}{ Facilitators } \\
\hline Flexible work schedule & 3,27 & 1,13 & 3,86 & 0,76 & 3,56 & 1,22 & 3,52 & 1,08 \\
\hline Less work obligations & 2,57 & 1,17 & 3,18 & 1,25 & 2,56 & 1,22 & 2,74 & 1,23 \\
\hline Active for job & 1,61 & 0,75 & 2,18 & 1,19 & 1,89 & 1,05 & 1,85 & 0,99 \\
\hline No work travel & 2,84 & 1,16 & 3,11 & 1,20 & 4,00 & 0,92 & 3,23 & 1,20 \\
\hline Less social obligations & 2,93 & 1,17 & 3,46 & 1,26 & 3,48 & 1,01 & 3,23 & 1,18 \\
\hline Access to facilities & 2,57 & 1,25 & 3,39 & 1,29 & 3,48 & 0,89 & 3,05 & 1,24 \\
\hline Taking care of children & 1,98 & 1,19 & 1,93 & 1,15 & 1,52 & 0,89 & 1,84 & 1,11 \\
\hline Online workouts & 2,84 & 1,18 & 2,89 & 1,29 & 2,93 & 1,39 & 2,88 & 1,26 \\
\hline Good weather & 3,86 & 0,85 & 3,79 & 0,83 & 3,96 & 1,09 & 3,87 & 0,91 \\
\hline Mean & 2,72 & & 3,09 & & 3,04 & & 2,91 & \\
\hline \multicolumn{9}{|l|}{ Barriers } \\
\hline Work-related fatigue & 2,86 & 1,21 & 2,36 & 1,19 & 2,37 & 1,28 & 2,59 & 1,24 \\
\hline No time due to job & 2,77 & 1,12 & 2,21 & 1,23 & 2,00 & 1,11 & 2,40 & 1,19 \\
\hline Not with colleagues & 2,48 & 1,27 & 1,64 & 1,06 & 2,04 & 1,19 & 2,12 & 1,23 \\
\hline No active transportation & 3,77 & 1,24 & 3,00 & 1,39 & 1,74 & 0,98 & 3,00 & 1,47 \\
\hline Care ill family & 1,43 & 0,70 & 1,21 & 0,42 & 1,33 & 0,62 & 1,34 & 0,61 \\
\hline Care for children & 1,91 & 1,29 & 1,46 & 0,88 & 1,48 & 0,98 & 1,67 & 1,12 \\
\hline Poor health & 1,59 & 0,95 & 1,43 & 0,74 & 1,26 & 0,53 & 1,45 & 0,80 \\
\hline Fear of breaking social distance & 2,55 & 1,47 & 1,82 & 0,91 & 2,07 & 1,24 & 2,21 & 1,30 \\
\hline Closed sport facilities & 3,66 & 1,64 & 2,50 & 1,37 & 2,33 & 1,47 & 2,97 & 1,63 \\
\hline No group activities & 2,93 & 1,55 & 2,39 & 1,13 & 2,19 & 1,50 & 2,58 & 1,45 \\
\hline No social support & 2,50 & 1,36 & 2,04 & 1,00 & 1,70 & 0,82 & 2,15 & 1,17 \\
\hline Time spent in household chores & 2,98 & 1,34 & 2,54 & 1,23 & 2,33 & 1,27 & 2,68 & 1,31 \\
\hline Not allowed to go outdoors & 2,80 & 1,51 & 1,65 & 0,69 & 1,87 & 1,22 & 2,22 & 1,34 \\
\hline Mean & 2,63 & & 2,02 & & 1,90 & & 2,26 & \\
\hline
\end{tabular}

Figures 2 and 3 provide the average rating of facilitators and barriers, respectively, to physical activity during the COVID-19 lockdown, comparing among predominant motivational profiles. The facilitators and 
barriers to physical activity during COVID-19 were perceived similarly by the intrinsic-motivated and extrinsic-motivated groups. The a-motivated group rated the facilitators considerably lower and the barriers considerably higher than the other two groups. 'Good weather' and 'flexible work schedule' were the first and second highest-rated facilitators by the three groups. 'No work travel' was in third place for the intrinsic-motivated (mean $=3.40$, SD 1.16) and a-motivated (mean $=2.89$, SD 1.36) groups. 'Less social obligations' was the third most important facilitator to physical activity for the extrinsic-motivated group (mean $=3.33$, SD 1.17). 'No active transportation' was the highest-rated barrier for the a-motivated $($ mean $=4.33$, SD 1.0) and extrinsic-motivated (mean $=3.07$, SD 1.39) groups. The second most relevant barrier to the a-motivated group was the fear to risk social distancing (mean $=4.00, S D 1.12$ ), followed by the time spent in 'household chores' and 'not allowed to go outdoors' (mean=3.89, SD 0.93). 'Closed facilities' and 'no-group activities' were the second and third most relevant barriers for the extrinsicmotivated group (means $=2.96$ and 2.67, respectively) .

\section{Discussion}

The objective of this study was to investigate the motivational profile, facilitators, and barriers that influenced an eventual change in physical activity while working remotely due to the COVID-19 lockdown. The results of the online survey show that the switch to remote work affected the physical behavior of $71 \%$ of the respondents, with $27 \%$ becoming more, and $44 \%$ becoming less physically active during the COVID-19 lockdown. This first conclusion follows the mixed results found in literature, where some studies report a decrease in global physical activity during the COVID-19 lockdown $(39,40)$, and others report an increase in indoor exercise activities (21).

Secondly, participants who reported becoming more active during the COVID-19 lockdown scored significantly higher on intrinsic motivation than the group who became less active. These results suggest that those who are intrinsically motivated to be physically active, not only have found strategies to deal with the constraint of working from home during the COVID-19 lockdown, but also made use of the facilitators to increase their activity level. This finding is in line with the idea that motivation and resilience are intertwined (41), and that intrinsic motivation fosters resilience. On the contrary, those who reported higher scores on a-motivation perceived the facilitators weaker and rated the barriers higher, and became less physically active during the COVID-19 lockdown. Our results are in line with other findings in the literature suggesting that individuals with more self-determined motivation profiles (leaning towards intrinsic motivation) were associated with higher participation in physical activity $(42,43)$.

Our findings have implications for the design of interventions to promote physical activity among office workers. Firstly, we highlight the importance of considering the motivational profile when designing personalized strategies to encourage physical activity while working from home. Whereas all individuals despite the predominant motivational profile considered 'good weather' and 'flexible work schedule' the most relevant facilitators to be physically active, only the intrinsic-motivated group seemed to be able to act upon these facilitators. When defining strategies to promote physical activity among remote office workers, one could think of interventions coupled to a weather forecast service. By knowing in advance 
the days or time slots when the weather will be favorable to outdoor activities, the office worker can be encouraged to plan time on the agenda to include active breaks. Secondly, being able to set their own work schedule and removing the (passive) commuting time has a positive impact on daily physical activity. The flexible working hours provide an opportunity to include active breaks in a population that has a predominantly sedentary lifestyle and is often characterized by a weekend-warrior profile (7-9). In this line, interventions to promote physical activity among office workers should encourage the individual to set a plan that fits their (new) working routines. While the intrinsically motivated group might have the internal resources to do this planning by themselves, the extrinsic-motivated group, and in particular the a-motivated group, might benefit from external support in this direction. Digital health solutions can support planning, reminding, and nudging the individual - as seen in the examples above. The management team of the organizations also has an important role as a source of extrinsic motivation, for example, by encouraging structured team lunch walks at distance, telephone walking meetings (instead of video conference), or active breaks. In these cases, digital health solutions can include gamified elements to increase motivation (e.g. leaderboard or challenges), as well as provide the means to share experiences (e.g. share a picture of the surroundings of your walk). Moreover, our results suggest the importance of fostering intrinsic motivation when developing (technology-based) interventions to promote physical activity among office workers working from home. One strategy is to find and promote activities that provide inner satisfaction and pleasure to the individual. Individuals are more likely to engage in activities that are pleasurable and at the same time, are more likely to be open to new activities, and initiate new behaviors, while they feel satisfied (44).

Our results also suggest that for those lacking motivation to be physically active, represented by the amotivated profile, it is particularly important to define strategies that include opportunistic physical activity in daily life. This a-motivated group, more likely to become less active during the switch to remote work, scored the 'lack of active transportation' considerably higher than the other barriers to physical activity. This suggests that active commuting, being an opportunistic form of physical activity might be the most important source of activity in the daily life of the a-motivated group. A specific strategy to promote physical activity among this group while working remotely passes through encouraging the planning of defined timeslots in the agenda corresponding to the time of active transportation to and from the workplace at the beginning and end of the day. The examples above mentioned are based on the theory that individuals are more likely to take an action if they have previously committed to perform that action (45).

Within certain considerations, the results of this study might simulate the experience of remote work beyond the COVID-19 lockdown, as three-quarters of the participants reported living in the Netherlands, where a 'soft lockdown' took place during the period in which this study took place. The soft lockdown means that sport- and entertainment facilities (e.g. cinemas and clubs) were closed, group activities were discouraged, but the population was incentivized to go outdoors alone or with members of the household while keeping social distancing. Individual activities, such as running, were also encouraged. While 'closure of sports facilities' is a temporary constraint caused by the COVID-19 lockdown, the lack of active transportation is an important barrier to consider when designing strategies to promote physical activity 
among office workers working remotely. In the Netherlands, where most participants come from, cycling is a popular means of transport $(46,47)$ and $26 \%$ of all trips are made cycling $(48)$. Without the need to cycle to work and with fewer social obligations, active transportation loosened its relevance on daily physical activity during remote office work. Future research should focus on translating the findings of this study into specific requirements for interventions promoting physical activity among office workers working from home and evaluate its effectiveness. Additionally, a larger-scale survey should be performed among remote office workers not constrained by the COVID-19 restrictions.

\section{Conclusion}

The results of the exploratory study suggest that, based on the experience during the COVID-19 lockdown, remote work can indeed provide facilitators to engage in more physical activity, although the motivational profile is important to act upon. Especially for individuals lacking the motivation to be physically active, making use of the flexible work opportunities together with the weather forecast services to include active breaks in the daily workday, and defining moments of the day to compensate for lack of active transportation to and from the workplace, are strategies likely to support office workers becoming more active, despite their sedentary occupational activity.

\section{Abbreviations}

COVID-19: coronavirus disease 2019

SMS-II: Sports Motivation Scale-II

\section{Declarations}

\section{Ethics approval and consent to participate}

The research was performed following the Declaration of Helsinki. Written informed consent was obtained from all subjects before starting the online survey. This study did not require the approval of the Medical Ethical Review Board, according to the Dutch Medical Research Involving Human Subjects Act (WMO) (37), as all subjects were competent individuals and the study did not involve any interventions or treatments.

\section{Consent for publication}

Not applicable.

\section{Availability of data and materials}

The datasets used and/or analyzed during the current study are available from the corresponding author on reasonable request. 


\section{Competing interests}

The authors declare that they have no competing interests.

\section{Funding}

This work was carried out in the context of the SmartWork project, funded by the European Commission under Grant Agreement number 826343.

\section{Authors' contribution}

$\mathrm{MC}$ contributed to the conception and design of the work, performed the analysis and interpretation of the data, and drafted the manuscript. RB contributed to the conception and design of the work, lead the data acquisition, and contributed to the analysis and interpretation of the data. MT has substantively revised the work. All authors read and approved the final manuscript.

\section{Acknowledgments}

Not applicable

\section{References}

1. World Health Organization, editor. Global health risks: mortality and burden of disease attributable to selected major risks. Geneva: World Health Organization; 2009. 62 p.

2. Smith L, McCourt O, Sawyer A, Ucci M, Marmot A, Wardle J, et al. A review of occupational physical activity and sedentary behaviour correlates. Occup Med (Lond). 2016 Apr 1;66(3):185-92.

3. Prince SA, Elliott CG, Scott K, Visintini S, Reed JL. Device-measured physical activity, sedentary behaviour and cardiometabolic health and fitness across occupational groups: a systematic review and meta-analysis. International Journal of Behavioral Nutrition Physical Activity. 2019 Apr;2(1):30. 16 .

4. Daneshmandi H, Choobineh A, Ghaem H, Karimi M. Adverse Effects of Prolonged Sitting Behavior on the General Health of Office Workers. J Lifestyle Med. 2017 Jul;7(2):69-75.

5. Janwantanakul P, Pensri P, Jiamjarasrangsri V, Sinsongsook T. Prevalence of self-reported musculoskeletal symptoms among office workers. Occup Med (Lond). 2008 Sep;58(6)(1):436-8.

6. Hogg-Johnson S, van der Velde G, Carroll LJ, Holm LW, Cassidy JD, Guzman J, et al. The burden and determinants of neck pain in the general population: results of the Bone and Joint Decade 20002010 Task Force on Neck Pain and Its Associated Disorders. Spine. 2008 Feb 15;33(4 Suppl):S39-51.

7. Gubelmann C, Vollenweider P, Marques-Vidal P. Of weekend warriors and couch potatoes: Socioeconomic determinants of physical activity in Swiss middle-aged adults. Prev Med. 2017;105:350-5.

8. Shuval K, Li Q, Gabriel KP, Tchernis R. Income, physical activity, sedentary behavior, and the 'weekend warrior' among U.S. adults. Prev Med. 2017 Oct;1:103:91-7. 
9. Clemes SA, O'Connell SE, Edwardson CL. Office workers' objectively measured sedentary behavior and physical activity during and outside working hours. J Occup Environ Med. 2014 Mar;56(3):298303.

10. O'Donovan G, Lee I-M, Hamer M, Stamatakis E. Association of "Weekend Warrior" and Other Leisure Time Physical Activity Patterns With Risks for All-Cause, Cardiovascular Disease, and Cancer Mortality. JAMA Intern Med. 2017 Mar 1;177(3):335-42.

11. Shiroma EJ, Lee I-M, Schepps MA, Kamada M, Harris TB. Physical Activity Patterns and Mortality: The Weekend Warrior and Activity Bouts. Med Sci Sports Exerc. 2019;51(1):35-40.

12. Ekelund U, Steene-Johannessen J, Brown WJ, Fagerland MW, Owen N, Powell KE, et al. Does physical activity attenuate, or even eliminate, the detrimental association of sitting time with mortality? A harmonised meta-analysis of data from more than 1 million men and women. The Lancet. 2016 Sep;24(10051):1302-10. 388(.

13. Dunstan DW, Wiesner G, Eakin EG, Neuhaus M, Owen N, LaMontagne AD, et al. Reducing office workers' sitting time: rationale and study design for the Stand Up Victoria cluster randomized trial. BMC Public Health. 2013 Dec;13(1):1057.

14. Renaud LR, Speklé EM, Beek AJ, van der, Ploeg HP van der, Pasman HR, Huysmans MA. The user and non-user perspective: Experiences of office workers with long-term access to sit-stand workstations. PLOS ONE. 2020 Jul;28(7):e0236582. 15(.

15. Nooijen CFJ, Blom V, Ekblom Ö, Heiland EG, Larisch L-M, Bojsen-Møller E, et al. The effectiveness of multi-component interventions targeting physical activity or sedentary behaviour amongst office workers: a three-arm cluster randomised controlled trial. BMC Public Health. 2020 Sep 1;20(1):1329.

16. Freak-Poli RL, Cumpston M, Albarqouni L, Clemes SA, Peeters A. Workplace pedometer interventions for increasing physical activity. Cochrane Database of Systematic Reviews [Internet]. 2020 [cited 2020 Sep 11];(7). Available from: https://www.readcube.com/articles/10.1002\%2F14651858.CD009209.pub3.

17. Damen I, Brombacher H, Lallemand C, Brankaert R, Brombacher A, van Wesemael P, et al. A Scoping Review of Digital Tools to Reduce Sedentary Behavior or Increase Physical Activity in Knowledge Workers. International Journal of Environmental Research Public Health. 2020 Jan;17(2):499.

18. Parmet WE, Sinha MS. Covid-19 - The law and limits of quarantine. New England Journal of Medicine Massachussetts Medical Society. 2020;Vol. 382:E281-3.

19. Mattioli AV, Sciomer S, Cocchi C, Maffei S, Gallina S. "Quarantine during COVID-19 outbreak: changes in Diet and physical activity increase the risk of cardiovascular disease". Nutrition, Metabolism and Cardiovascular Diseases. 2020 May 30.

20. Shahidi SH, Stewart Williams J, Hassani F. Physical activity during COVID-19 quarantine. Acta Paediatrica. 2020 Jun 18;n/a(n/a):apa.15420.

21. The Impact of the Global Pandemic on Human Activity. Part III [Internet]. Garmin Blog. 2020 [cited 2020 Aug 14]. Available from: https://www.garmin.com/en-US/blog/fitness/the-impact-of-the-globalpandemic-on-human-activity-part-iii/. 
22. Reynolds F. Strategies for facilitating physical activity and wellbeing: A health promotion perspective. Vol. 64, British Journal of Occupational Therapy. SAGE PublicationsSage UK: London, England; 2001. p. 330-6.

23. Kilpatrick M, Blizzard L, Sanderson K, Teale B, Jose K, Venn A. Barriers and facilitators to participation in workplace health promotion (WHP) activities: Results from a cross-sectional survey of public-sector employees in Tasmania, Australia. Health Promotion Journal of Australia. 2017 Dec;28(3):225-32.

24. Leslie JH, Braun KL, Novotny R, Mokuau N. Factors affecting healthy eating and physical activity behaviors among multiethnic blue- and white-collar workers: a case study of one healthcare institution. Hawai'i journal of medicine public health: a journal of Asia Pacific Medicine Public Health. 2013 Sep;72(9):300-6.

25. Planchard JH, Corrion K, Lehmann L, D'Arripe-Longueville F. Worksite physical activity barriers and facilitators: A qualitative study based on the transtheoretical model of change. Frontiers in Public Health. 2018 Nov 15;6(NOV):326.

26. Mailey EL, Huberty J, Dinkel D, McAuley E. Physical activity barriers and facilitators among working mothers and fathers. BMC Public Health. 2014 Dec 27;14(1):657.

27. Tavares LS, Plotnikoff RC. Not enough time? Individual and environmental implications for workplace physical activity programming among women with and without young children. Health Care for Women International. 2008 Mar 14;29(3):244-81.

28. Borodulin K, Sipilä N, Rahkonen O, Leino-Arjas P, Kestilä L, Jousilahti P, et al. Socio-demographic and behavioral variation in barriers to leisure-time physical activity. Scandinavian Journal of Public Health. 2016 Feb 21;44(1):62-9.

29. Cole JA, Tully MA, Cupples ME. 'They should stay at their desk until the work's done': a qualitative study examining perceptions of sedentary behaviour in a desk-based occupational setting Public Health. BMC Research Notes. 2015 Dec;17(1):683. 8(.

30. McPhail SM, Schippers M, Marshall AL, Waite M, Kuipers P. Perceived barriers and facilitators to increasing physical activity among people with musculoskeletal disorders: A qualitative investigation to inform intervention development. Clinical Interventions in Aging. 2014 Dec 5;9:2113-22.

31. Kadariya S, Aro AR. Barriers and facilitators to physical activity among urban residents with diabetes in Nepal. Soundy A, editor. PLoS ONE. 2018 Jun 28;13(6):e0199329.

32. Uijtdewilligen L, Waters $\mathrm{CNH}$, Aw S, Wong ML, Sia A, Ramiah A, et al The Park prescription study: Development of a community-based physical activity intervention for a multi-ethnic Asian population. Nocera JR, editor. PLoS ONE. 2019 Jun 11;14(6):e0218247.

33. Deci E, Ryan RM. Intrinsic Motivation and Self-Determination in Human Behavior [Internet]. Springer US. 1985 [cited 2020 May 31]. (Perspectives in Social Psychology). Available from: https://www.springer.com/gp/book/9780306420221.

34. Pelletier LG, Rocchi MA, Vallerand RJ, Deci EL, Ryan RM. Validation of the revised sport motivation scale (SMS-II). Psychol Sport Exerc. 2013;14(3):329-41. 
35. van Velsen L, Broekhuis M, Jansen-Kosterink S, op den Akker H Tailoring Persuasive Electronic Health Strategies for Older Adults on the Basis of Personal Motivation: Web-Based Survey Study. Journal of Medical Internet Research. 2019 Sep 6;21(9):11759.

36. Olsen HM, Brown WJ, Kolbe-Alexander T, Burton NW. Physical activity and sedentary behaviour in a flexible office-based workplace: Employee perceptions and priorities for change. Health Promotion Journal of Australia. 2018;29(3):344-52.

37. Ministerie van Binnenlandse Zaken en Koninkrijksrelaties. Wet medisch-wetenschappelijk onderzoek met mensen [Internet]. [cited 2020 Dec 19]. Available from:

https://wetten.overheid.nl/BWBR0009408/2020-01-01.

38. Ryan RM, Deci EL. Self-determination theory and the facilitation of intrinsic motivation, social development, and well-being. Am Psychol. 2000;55(1):68-78.

39. Tison GH, Avram R, Kuhar P, Abreau S, Marcus GM, Pletcher MJ, et al. Worldwide Effect of COVID-19 on Physical Activity: A Descriptive Study. Annals of Internal Medicine [Internet]. 2020 Jun 29 [cited 2020 Sep 11]; Available from: https://www.acpjournals.org/doi/10.7326/M20-2665.

40. Ainsworth BE, Li F. Physical activity during the coronavirus disease-2019 global pandemic. J Sport Health Sci. 2020 Jul;9(4):291-2.

41. Resnick B. The Relationship Between Resilience and Motivation. In: Resnick B, Gwyther LP, Roberto KA, editors. Resilience in Aging: Concepts, Research, and Outcomes [Internet]. Cham: Springer International Publishing; 2018 [cited 2020 Sep 11]. p. 221-44. Available from: https://doi.org/10.1007/978-3-030-04555-5_12.

42. Castonguay A, Miquelon P. Motivational profiles for physical activity among adults with type 2 diabetes and their relationships with physical activity behavior. Health Psychology and Behavioral Medicine. 2017 Jan 21;5(1):110-28.

43. Gourlan M, Trouilloud D, Boiché J. Motivational Profiles for Physical Activity Practice in Adults with Type 2 Diabetes: A Self-Determination Theory Perspective. Behavioral Medicine. 2016 Oct $11 ; 42(4): 227-37$.

44. Fredrickson BL. Positive Emotions Broaden and Build. In: Devine P, Plant A, editors. Advances in Experimental Social Psychology [Internet]. Academic Press; 2013 [cited 2020 Sep 11]. p. 1-53. Available from: http://www.sciencedirect.com/science/article/pii/B9780124072367000012.

45. Gollwitzer PM. Implementation Intentions: Strong Effects of Simple Plans. American Psychologist. 1999;11.

46. Pucher J, Dijkstra L. Promoting Safe Walking and Cycling to Improve Public Health: Lessons from The Netherlands and Germany. Am J Public Health. 2003;93(9):1509-16.

47. Fishman E, Schepers P, Kamphuis CBM. Dutch cycling: Quantifying the health and related economic benefits. Am J Public Health. 2015;105(8):e13-5.

48. Kennisinstituut voor Mobiliteitsbeleid. Mobiliteitsbeeld 2019 [Internet]. 2019. Available from: https://www.kimnet.nl/mobiliteitsbeeld/mobiliteitsbeeld-2019\#/toc/1.3. 


\section{Figures}

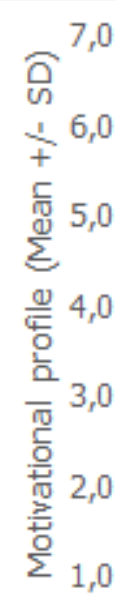

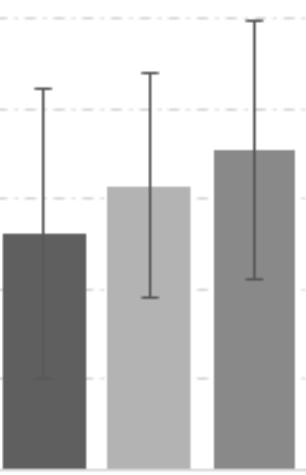

Intrinsic Motivation

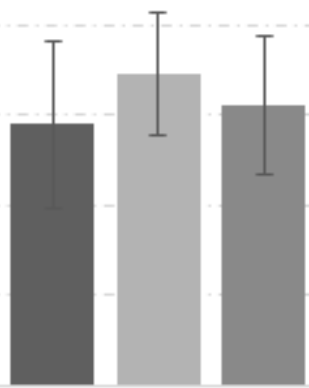

Extrinsic Motivation

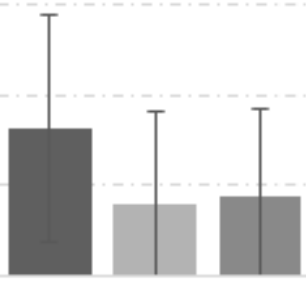

Amotivation

- less-active nually-active more-active

\section{Figure 1}

Average score of motivational profile to engage in physical activity and respective standard deviation per perceived change in physical activity during the COVID-19 lockdown. Extrinsic motivation encompasses integrated regulation, identified regulation, introjected regulation, and external regulation

\section{Facilitators physical activity during the COVID-19 lock- down}

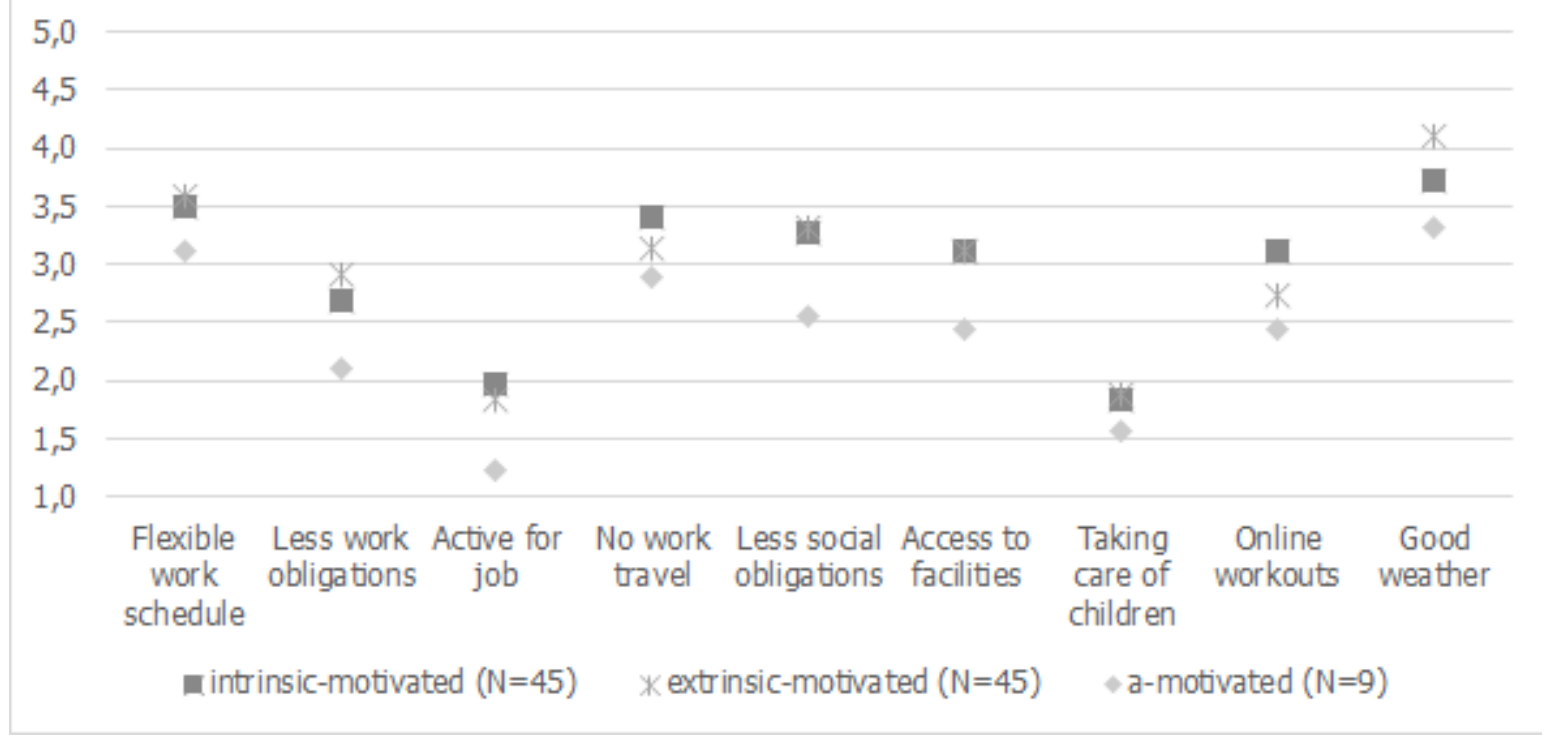

\section{Figure 2}

Mean scores of the relevance of each facilitator to physical activity during the COVID-19 lockdown separated by predominant motivational profile: intrinsic-motivated $(N=45)$, extrinsic-motivated $(N=45)$, 
and a-motivated $(\mathrm{N}=9)$. Participants were asked to rate how much they agreed with the facilitators on a scale from 1 (completely disagree) to 5 (completely agree)

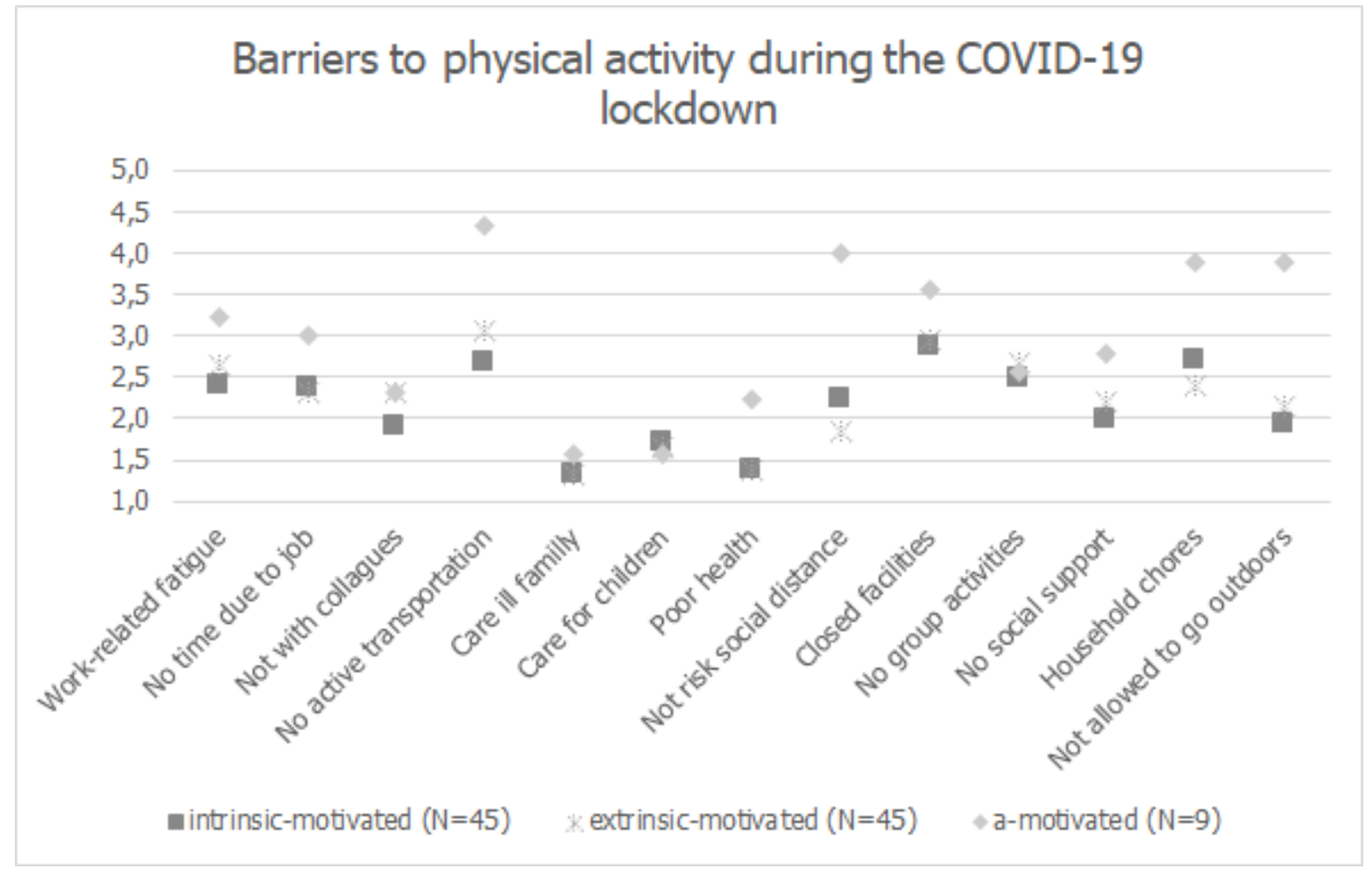

\section{Figure 3}

Mean scores of the relevance of each barrier to physical activity during the COVID-19 lockdown separated by predominant motivational profile: intrinsic motivation $(\mathrm{N}=45)$, extrinsic motivation $(\mathrm{N}=45)$, and amotivation $(\mathrm{N}=9)$. Participants were asked to rate how much they agreed with the barriers on a scale from 1 (completely disagree) to 5 (completely agree) 